Article

\title{
Degradation of Carbendazim by Molecular Hydrogen on Leaf Models
}

\author{
Tong Zhang ${ }^{1}$, Yueqiao Wang ${ }^{1}$, Zhushan Zhao ${ }^{1}$, Sheng $X \mathrm{u}^{2}$ and Wenbiao Shen ${ }^{1, *(\mathbb{D})}$ \\ 1 Laboratory Center of Life Sciences, College of Life Sciences, Nanjing Agricultural University, \\ Nanjing 210095, China; 2020116098@stu.njau.edu.cn (T.Z.); 2019116098@njau.edu.cn (Y.W.); \\ 2021816131@stu.njau.edu.cn (Z.Z.) \\ 2 Institute of Botany, Jiangsu Province and Chinese Academy of Sciences, Nanjing 210014, China; \\ xusheng@cnbg.net \\ * Correspondence: wbshenh@njau.edu.cn; Tel.: +86-25-84-399-032; Fax: +86-25-84-396-542
}

Citation: Zhang, T.; Wang, Y.; Zhao, Z.; Xu, S.; Shen, W. Degradation of Carbendazim by Molecular Hydrogen on Leaf Models. Plants 2022, 11, 621. https://doi.org/ $10.3390 /$ plants 11050621

Academic Editor: John Hancock

Received: 7 February 2022

Accepted: 23 February 2022

Published: 25 February 2022

Publisher's Note: MDPI stays neutral with regard to jurisdictional claims in published maps and institutional affiliations.

Copyright: (C) 2022 by the authors. Licensee MDPI, Basel, Switzerland. This article is an open access article distributed under the terms and conditions of the Creative Commons Attribution (CC BY) license (https:// creativecommons.org/licenses/by/ $4.0 /)$.

\begin{abstract}
Although molecular hydrogen can alleviate herbicide paraquat and Fusarium mycotoxins toxicity in plants and animals, whether or how molecular hydrogen influences pesticide residues in plants is not clear. Here, pot experiments in greenhouse revealed that degradation of carbendazim (a benzimidazole pesticide) in leaves could be positively stimulated by molecular hydrogen, either exogenously applied or with genetic manipulation. Pharmacological and genetic increased hydrogen gas could increase glutathione metabolism and thereafter carbendazim degradation, both of which were abolished by the removal of endogenous glutathione with its synthetic inhibitor, in both tomato and in transgenic Arabidopsis when overexpressing the hydrogenase 1 gene from Chlamydomonas reinhardtii. Importantly, the antifungal effect of carbendazim in tomato plants was not obviously altered regardless of molecular hydrogen addition. The contribution of glutathione-related detoxification mechanism achieved by molecular hydrogen was confirmed. Our results might not only illustrate a previously undescribed function of molecular hydrogen in plants, but also provide an environmental-friendly approach for the effective elimination or reduction of pesticides residues in crops when grown in pesticides-overused environmental conditions.
\end{abstract}

Keywords: hydrogen gas; carbendazim degradation; glutathione metabolism; detoxification system; redox balance

\section{Introduction}

Pesticides are indispensable for sustained food production [1]. However, excessive use of pesticides, including fungicides, could result in pesticide pollution of vegetables and environmental contamination. More importantly, fungicides can enter the human body and the food chain through foods, polluted air, and water. Therefore, human health is currently being threatened by the continued use of fungicides [2]. Carbendazim (CAR; methyl 1H-benzimidazol-2-ylcarbamate), a benzimidazole fungicide, is generally used in treatment and control of fungal diseases in vegetables, fruits, flowers, etc. [3]. Since $\beta$-tubulin is the target of CAR, its antifungal mechanism could be contributed to interfere with the formation of the spindle during the mitosis of pathogenic bacteria [4].

Normally, CAR remains on the plant surface, or is absorbed by plants and then accumulates at the end of the food chain, ultimately posing a serious threat to human health. Importantly, excess CAR has been reported to disrupt the human endocrine system. At low concentrations, this chemical can even damage the mammalian liver, reproductive tissues, and endocrine [5]. Therefore, there is an urgent need to develop effective strategies to reduce CAR residues in agricultural products.

The degradation of CAR is mainly photochemical catalytic degradation and biodegradation, but the process is relatively slow [6]. Thus, research on accelerating the degradation of carbendazim in plants and the environment has attracted more attention, especially 
with an environmental-friendly approach. For example, previous research discovered the nitric oxide (NO), a natural by-product of nitrogen metabolism [7], can participate in the degradation process of chlorothalonil, a broad-spectrum chlorine fungicide, achieved by brassinosteroid [8].

Hydrogen gas $\left(\mathrm{H}_{2}\right)$ is extremely small and was previously regarded as a relatively inert molecule. During the last decade, the biology of molecular hydrogen in animals has experiencing a surge of discoveries after Japanese scientists discovered that $\mathrm{H}_{2}$ is a novel selective antioxidant in rats [9]. In contrast to the clear picture of $\mathrm{H}_{2}$ in animals [10], the progress of $\mathrm{H}_{2}$ functions in plants is just beginning [11]. Initially in plant biology, $\mathrm{H}_{2}$ production is thought to be increased under various abiotic stresses and the normal growth conditions [12,13]. Afterwards, this gas was confirmed to be produced as an obligate by-product of the nitrogenase reaction [14], although other synthetic pathways of $\mathrm{H}_{2}$ are still unknown.

Further experiments confirmed that exogenously applied with hydrogen-rich water (HRW) or the fumigation with $\mathrm{H}_{2}$ could play vital roles in plant growth, development, and environmental responsiveness $[15,16]$. The degradation of fungicides remaining on the surface of plants could be accelerated by HRW through brassinosteroids signaling pathway, such as chlorothalonil (CHT) [17]. However, CHT was hardly absorbed by plants compared with CAR [18]. Genetic evidence showed that the expression of the hydrogenase1 gene (CrHYD1) from Chlamydomonas reinhardtii not only increased endogenous $\mathrm{H}_{2}$ production, but also confers Arabidopsis tolerance against salinity [19] and drought stress [20]. Additionally, $\mathrm{H}_{2}$ could influence nitric oxide [21], abscisic acid [22], auxin [23], melatonin [19], and glutathione [24] signaling in plants.

This study wants to elucidate whether the application of $\mathrm{H}_{2}$ could stimulate the degradation of CAR, a systemic fungicide applied in agriculture. First, genetic and physiological evidence showed that endogenous $\mathrm{H}_{2}$ plays an important role in regulating CAR degradation in plant leaves through intensifying glutathione synthesis. Based on these results, we further suggest that CAR degradation might be controlled by genetic manipulation of endogenous $\mathrm{H}_{2}$ or exogenously applied with $\mathrm{H}_{2}$. Given the inherent toxicity of carbendazim and the intentional release into the environment [25], our results may contribute to the application of molecular hydrogen in agriculture and human health.

\section{Results and Discussion}

\subsection{Exogenous $\mathrm{H}_{2}$ Control of CAR Degradation}

Though molecular hydrogen could enhance the metabolism of CHT in plants [17], the adsorption characteristics between CHT and CAR were entirely different. CHT was just attached to the leaf surface and hardly absorbed by plants, while CAR was absorbed into the plants and then exerted the medicinal effect. Thus, whether or how molecular hydrogen affects the metabolism of systemic fungicides in plants is still not clarified. To explore the problem above, tomato plants with six leaves were selected for the following experiments. Firstly, time curve analysis showed that after CAR addition, the absorption of this fungicide in tomato leaves was rapidly increased during the first $24 \mathrm{~h}$ period, followed by the progressive decline until $96 \mathrm{~h}$ (Figure S1). Therefore, tomato seedlings after treated with CAR for $24 \mathrm{~h}$ were used to assess the effect of exogenous molecular hydrogen on CAR degradation.

After the above CAR-treated seedlings were shifted to no CAR condition $\left(C A R \rightarrow \mathrm{dH}_{2} \mathrm{O}\right)$, its residue in leaves was moderately decreased during a $96-\mathrm{h}$ period (Figure $1 \mathrm{~A}$ ). This result was consistent with the former findings [26], reflecting the photochemical catalytic degradation and biodegradation of CAR. Meanwhile, we observed that CAR addition for $24 \mathrm{~h}$ could rapidly stimulate the $\mathrm{H}_{2}$ production, and reach the peak after $12 \mathrm{~h}$ (Figure $1 \mathrm{~B}$ ). These results demonstrated that the $\mathrm{H}_{2}$ concentration was increased in response to CAR. 
A

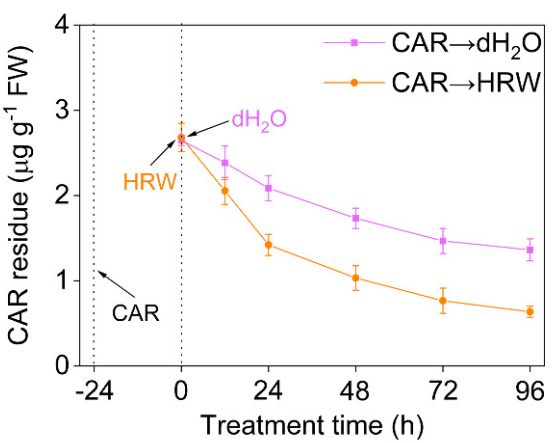

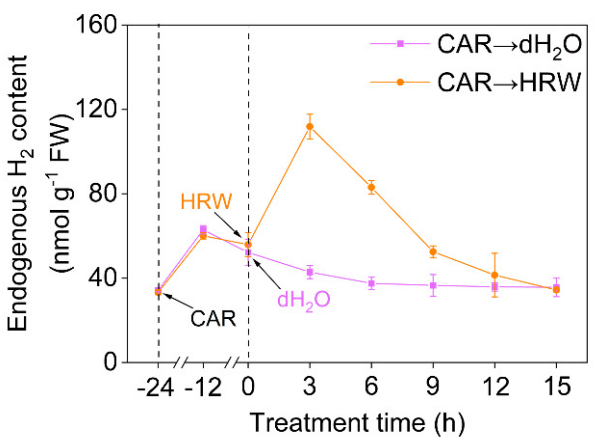

Figure 1. A possible link between the degradation of CAR and molecular hydrogen. Tomato seedlings at the six leaves stage were exposed to $10.46 \mathrm{mM} \mathrm{CAR}$ for $24 \mathrm{~h}$, followed by the treatment with $\mathrm{dH}_{2} \mathrm{O}$ and $\mathrm{HRW}$ for $24 \mathrm{~h}$. Afterwards, time course of changes in CAR degradation curve (A) and endogenous $\mathrm{H}_{2}$ contents (B) were determined. Error bars represent the standard deviation (SD; $\mathrm{n}=3$ ).

Subsequent experiments were performed to investigate whether this $\mathrm{H}_{2}$ increase was directed towards counteracting CAR phytotoxicity. When treated with saturated HRW, which contained $0.78 \mathrm{mM} \mathrm{H}_{2}$ produced by the electrolysis method, the degradation of CAR in tomato seedling leaves was remarkably intensified approximately in a time-dependent fashion (Figure 1A). For example, molecular hydrogen treated tomato leaves displayed residues of $86.2 \%, 68.1 \%, 59.6 \%, 52.2 \%$, and $46.6 \%$ compared to those of the non-HRW treatment at $12,24,48,72$, and $96 \mathrm{~h}$, respectively. Meanwhile, HRW addition could rapidly increase endogenous $\mathrm{H}_{2}$ content in CAR-treated tomato leaves, reaching the peak after $3 \mathrm{~h}$ (Figure 1B). Similar results were discovered in seedlings of rice [27], alfalfa [28], and Arabidopsis [22] when treated in stressed conditions. Therefore, we further confirmed that endogenous molecular hydrogen metabolism might be regulated by environmental stimuli [29].

To assess the above results, six common crops that usually use CAR [30], including radish, cucumber, rice, rapeseed, alfalfa, and pepper, were selected for the further experiments. As shown in Figure S2, it was clearly illustrated that saturated HRW could remarkably promote the degradation of CAR in the above-mentioned crops, implying that molecular hydrogen control of CAR degradation might be a universal event.

\subsection{Exogenous $\mathrm{H}_{2}$ Did Not Alter the Antifungal Effect of CAR}

Whether molecular hydrogen could influence the bactericidal effect of CAR is another concern. To answer this scientific question, Alternaria solani, which can cause several diseases on foliage, basal stems of seedlings, and fruits of tomato [31], were applied in PDA culture medium in the presence or absence of either HRW or CAR. After 10 days of inoculation, it was clearly observed that the colony diameter was differentially inhibited by CAR, when its concentrations were ranging from 2.62 to $20.92 \mathrm{mM}$ (Figure 2A,B). Importantly, the above inhibition achieved by CAR was not altered regardless of HRW addition. Thus, HRW might not repress the growth and development of pathogenic bacteria. Consistently, no significant differences in the disease rate of leaf were observed in fungus-infected tomato seedlings at the six-leaves stage with or without HRW treatments (Figure 2C-F). The above results clearly showed that the antifungal effect of CAR was not altered by HRW. It was an interesting finding. This result further confirmed the possibility that the detoxification pathway triggered by molecular hydrogen might be mediated by a specific route, rather than binding tubulin molecule and inhibiting its role in microtubule assembly. Certainly, these parallel events should be carefully explored. 
A

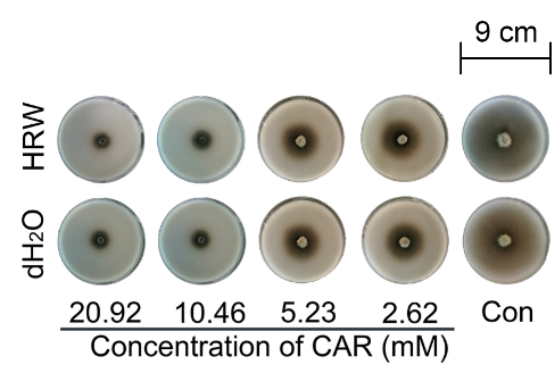

C

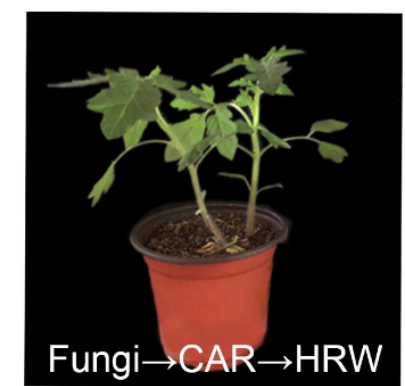

$E$
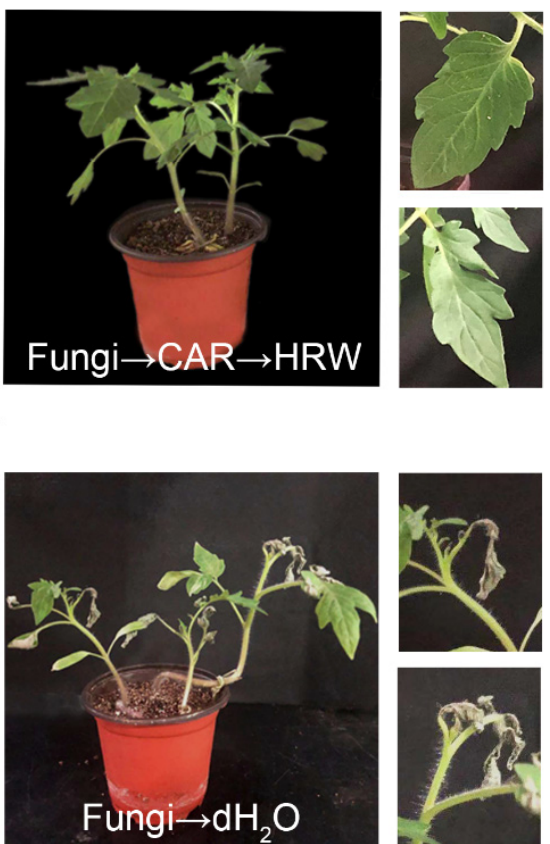

B

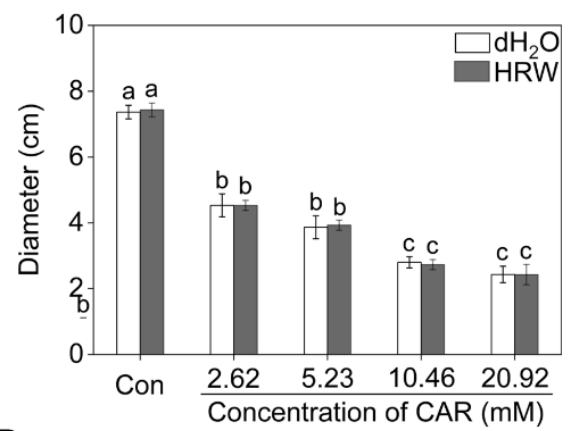

D
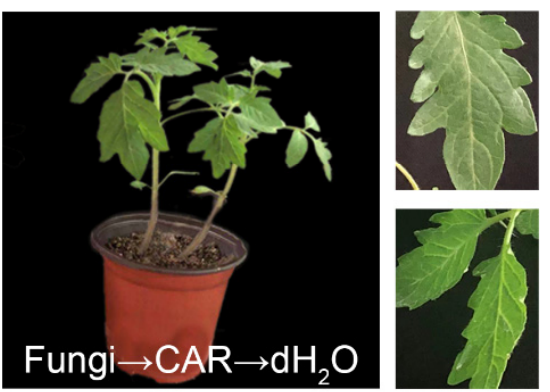

$\mathrm{F}$

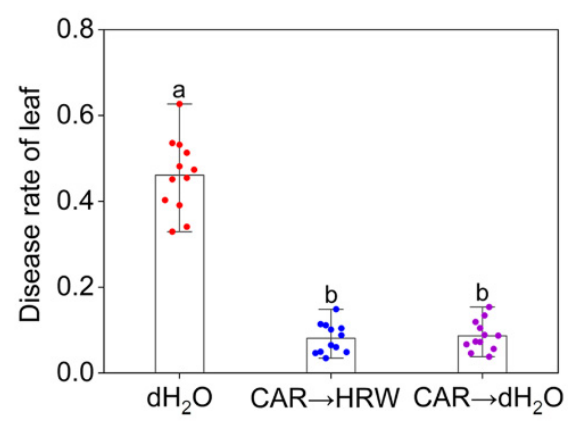

Figure 2. The antifungal effect of CAR was not affected by HRW. Alternaria solani was cultured in PDA culture mediums. After treatment for 10 days, the representative phenotypes were photographed (A). The diameter of the colony was counted (B). Tomato seedlings at the six-leaves stage were divided into three groups. The first and second groups were treated with $10.46 \mathrm{mM}$ CAR for $24 \mathrm{~h}$ after inoculated by Alternaria solani. Afterwards, the two groups were respectively treated with $\mathrm{HRW}$ ( $\mathrm{CAR} \rightarrow \mathrm{HRW}$ ) or distilled water ( $\mathrm{CAR} \rightarrow \mathrm{dH}_{2} \mathrm{O}$ ) every two days. The third group was inoculated with Alternaria solani for $24 \mathrm{~h}$ and treated with distilled water $\left(\mathrm{dH}_{2} \mathrm{O}\right)$ every two days. After 15 days, the representative phenotypes were photographed (C-E). The diseased leaves rate of three different treatments was counted $(\mathbf{F})$. The error bars represent the $\mathrm{SDs}(\mathrm{n}=3$ for $(\mathbf{B}), \mathrm{n}=12$ for $(\mathbf{F}))$, and the different letters indicate significantly different values $(p<0.05$ according to Tukey's multiple test).

\subsection{Glutathione Involvement in Molecular Hydrogen Control of CAR Degradation}

Since glutathione (GSH) is identified as an important detoxification compound and defensive signaling molecule in both human disease responses and plant adaptation to environmental stresses [32], the changes in GSH-metabolism and detoxification genes expression were analyzed by using RT-qPCR. As shown in Figure 3, CAR stimulated the expression of GS (encoding glutathione synthetase), GST genes (encoding glutathione $S$-transferase), GPX (encoding glutathione synthetase), $A B C 2$ (encoding ABC transporters), and CYP724B2 (encoding one of the members of brassinosteroids) in the plants [33,34]. It could be speculated that the enhancement of the above gene expression following exposure to CAR might be an initial defense response for intensifying the GSH-metabolism 
and detoxification systems. Afterwards, we observed that HRW addition could further stimulate the expression of the above genes compared to the $\mathrm{dH}_{2} \mathrm{O}$ control samples.

A
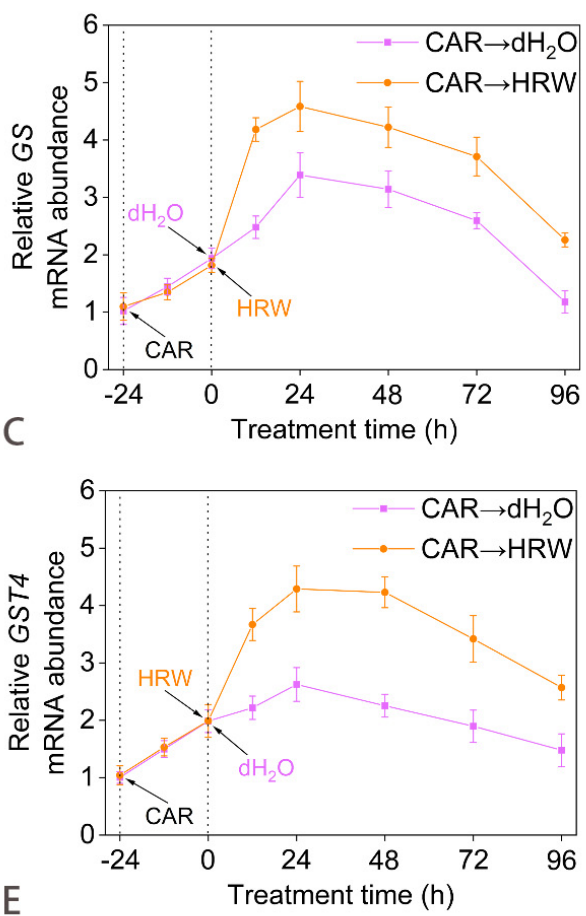

E

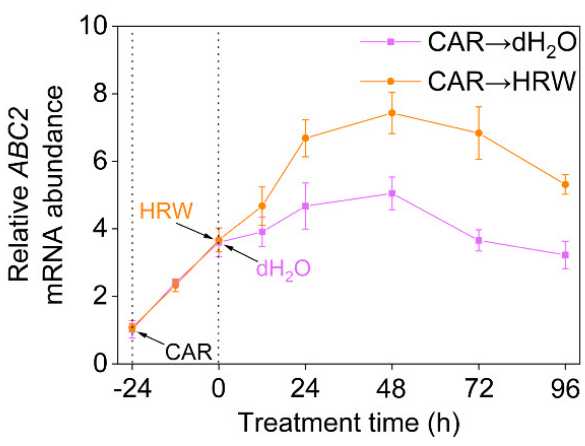

B
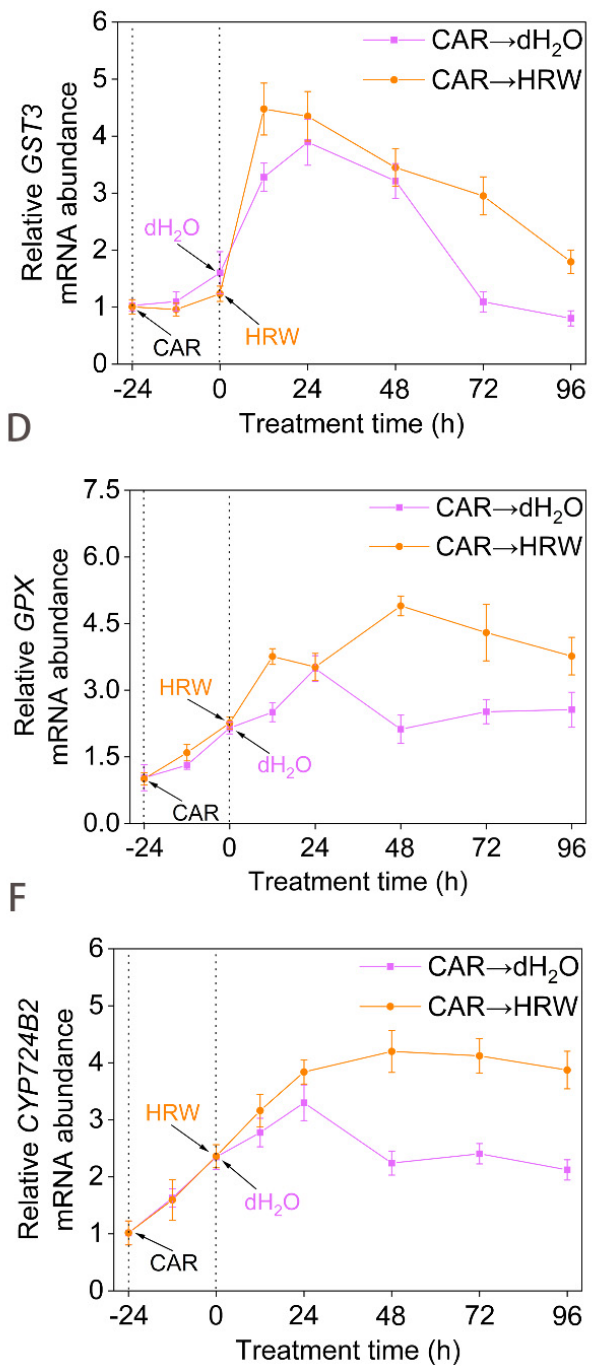

Figure 3. Time curve of GSH-metabolism and detoxification genes expression. Tomato seedlings at the six leaves stage were exposed to $10.46 \mathrm{mM} \mathrm{CAR}$ for $24 \mathrm{~h}$, followed by the treatment with $\mathrm{dH}_{2} \mathrm{O}$ or HRW for $24 \mathrm{~h}$. Afterwards, the time course of changes in GS (A), GST3 (B), GST4 (C), GPX (D), ABC2 (E), CYP724B2 (F) genes expression was determined. Error bars represent the standard deviation (SD; $\mathrm{n}=3)$.

Subsequently, endogenous GSH levels were monitored under the identical conditions. Although the pretreatment with CAR for $24 \mathrm{~h}$ could not obviously influence the changes of reduced GSH levels [34], the addition of HRW did trigger GSH production, peaking at $24 \mathrm{~h}$ after treatment, then followed by a gradual decrease, but still above the basal level (Figure 4A). Unlike the responses in reduced GSH, oxidized GSH (GSSG) production in tomato seedling leaves was stimulated by CAR, which was further maintained by HRW up to $48 \mathrm{~h}$ after treatment compared to non-HRW control samples (Figure 4B). A similar change in GSH pool, especially GSSG, achieved by CAR, was previously reported in tomato plants [26]. The above results clearly showed that an increase in the concentration of GSH might be one of the earliest responses participating in the signaling transduction triggered by molecular hydrogen in tomato leaves. Subsequent results revealed that GSH addition could improve photosynthetic characteristics. As expected, treatment with CAR could severely inhibit the values of the net photosynthetic rate (Pn), the maximum PSII 
quantum yield $(\mathrm{Fv} / \mathrm{Fm})$, and photochemical quenching coefficient (qP), reflecting the phytotoxicity of CAR (Figure S3A-C), which was also accompanied with the increased lipid peroxidation in tomato seedling leaves (TBARS; Figure S3D). After GSH addition, the above parameters could be differentially improved, especially with $5 \mathrm{mM}$ GSH exhibiting the maximal responses, which was used subsequently.

A

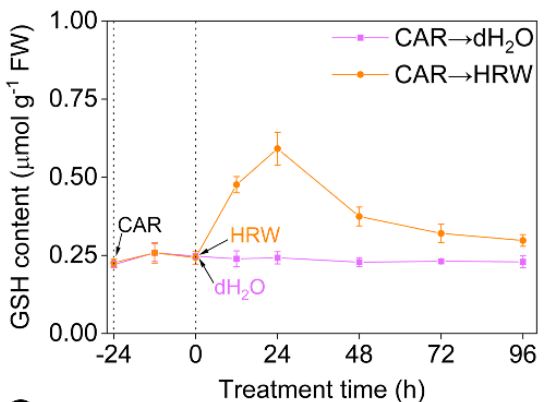

C
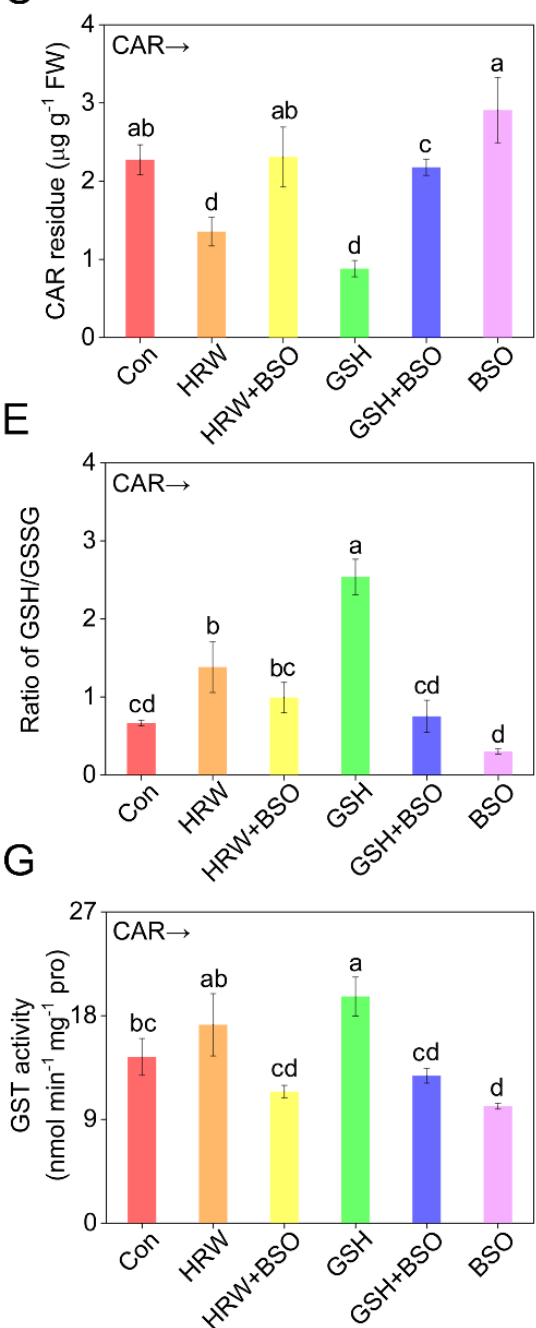

$\mathrm{B}$

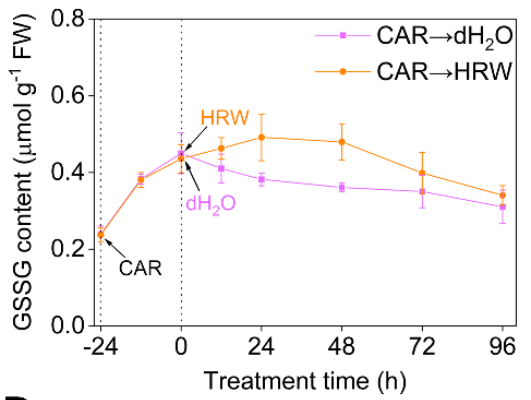

D
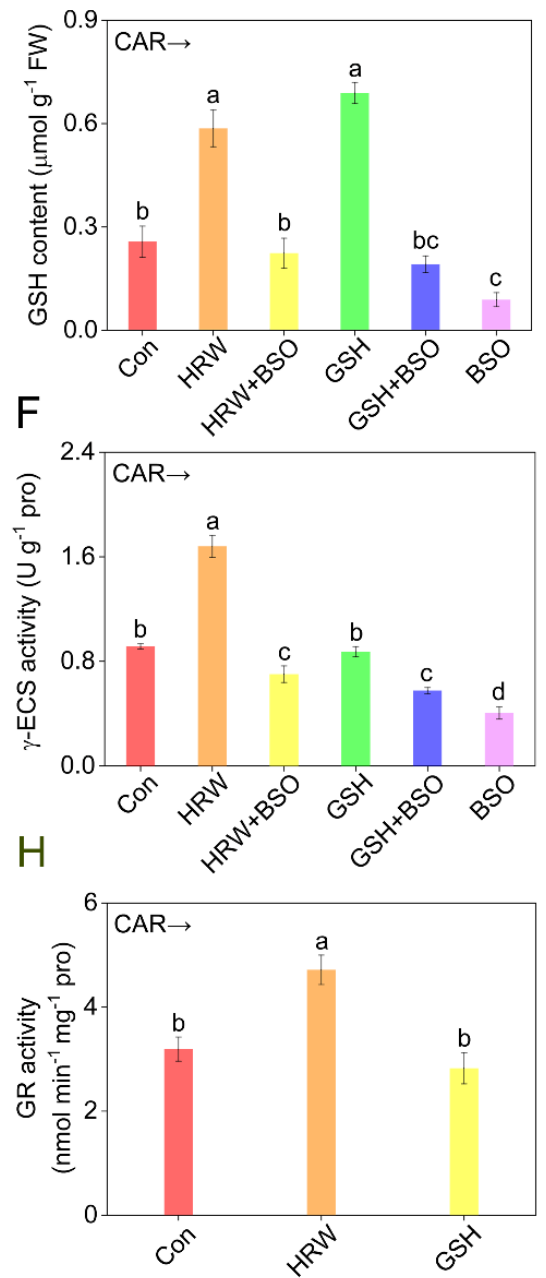

Figure 4. Changes in glutathione-related metabolism and CAR residues. Seedlings at the six-leaves stage were exposed to $10.46 \mathrm{mM} \mathrm{CAR}$ for $24 \mathrm{~h}$, followed by the treatment with $\mathrm{dH}_{2} \mathrm{O}$ (Con), $\mathrm{HRW}$, $\mathrm{GSH}$, or BSO, alone or their combinations. Afterwards, time-course changes in endogenous reduced GSH (A) and GSSG (B) contents were analyzed. After treatments for $24 \mathrm{~h}$, CAR residue (C), reduced GSH content (D), the ratio of GSH/GSSG (E), and $\gamma$-ECS (F), GST (G), and GR (H) activities in tomato leaves were determined. Error bars represent the standard deviation $(\mathrm{SD} ; \mathrm{n}=3)$. Bars with different letters are significantly different $(p<0.05)$ according to Tukey's multiple test. 
To assess the contribution of endogenous GSH in the response of CAR degradation achieved by molecular hydrogen, $\mathrm{L}$-buthionine-sulfoximine (BSO), an effective inhibitor of $\gamma$-glutamylcysteine synthetase $(\gamma$-ECS) responsible for GSH synthesis [35,36], was applied individually or simultaneously. Further experiments showed an obvious increase of endogenous GSH content, and importantly, a significant reduction in CAR content, after the addition of GSH (Figure 4C,D), mimicking the responses of HRW. By contrast, the above-mentioned results were remarkably abolished by BSO, reflecting the important function of endogenous GSH. Alone, BSO could result in the accumulation of CAR and in the depletion of GSH.

The GSH biosynthesis induction by molecular hydrogen was previously observed in the stressed conditions [37] or during lateral root development [24]. To further decipher the protective role of GSH in molecular hydrogen control of CAR degradation, GSH metabolism was examined. As shown in Figure 4E, in the presence of CAR, both HRW and especially GSH could significantly enhance the ratio of GSH/GSSG. Unlike the effect of exogenous GSH, the above response of HRW might be caused by the increased activity of $\gamma$-ECS (Figure 4F), an important enzyme catalyzed GSH synthesis [36]. These indicated the stimulation of GSH production achieved by molecular hydrogen via intensifying $\gamma$ ECS activity, and similar results were found in both animals and plants, especially under environmental stimuli [37]. Consistently, the above responses in GSH/GSSG and $\gamma$-ECS activity conferred by HRW were abolished by the removal of endogenous GSH in the presence of BSO, reflecting that the HRW control of the response is $\gamma$-ECS-dependent. When applied alone, BSO did result in negative effects.

Both glutathione $S$-transferase (GST) and glutathione reductase (GR) are two enzymes related to GSH metabolism. Between these, GR is responsible for reducing GSSG back to GSH [38]. Particularly, ample evidence showed that GSH control of organic compounds detoxification is closely associated with the reaction catalyzed by GST, and its product, GSH conjugates, could be transported into the vacuole [39]. Accordingly, the changes in GR and GST were investigated and compared in the presence or absence of HRW or GSH, with or without the addition of BSO.

For GST, further results clearly revealed that both HRW and GSH intensified its activities, which were further impaired by BSO (Figure 4G). Importantly, these data were correlated to changes in CAR residues (Figure 4C). These might be explained by the fact that CAR residues might be bound to GSH catalyzed by enhanced GST activity to form less reactive and toxic conjugates for subsequent transportation and degradation [40]. Similar changes were observed in the contents of nonprotein thiols (NPT; Figure S4A). Since NPT were closely associated with GSH conjugates, we further deduced that the stimulation of NPT synthesis achieved by molecular hydrogen might reflect the decomposition products of pesticide to some extent [41]. After the addition of CAR, unlike the response of GSH, HRW could remarkably increase the activity of GR (Figure $4 \mathrm{H}$ ). These changes also matched with the GSH content and the ratio of GSH and GSSG, further supporting the important function of endogenous GSH in the molecular hydrogen control of CAR degradation.

\subsection{Transcriptional Regulation of GSH-Metabolism and Detoxification Genes}

To probe the molecular mechanism underlying molecular hydrogen control of GSH synthesis, RT-qPCR was applied. As shown in Figure 5A-C, HRW strongly stimulated the expression of GR, GSH1 (encoding $\gamma$-ECS) [42], and GST2 in the presence of CAR, all of which were matched with the increased activities of GR (Figure 4H), $\gamma$-ECS (Figure 4F), and GST (Figure 4G), thus promoting endogenous GSH production in CAR-treated tomato seedling leaves (Figure 4A). 
A

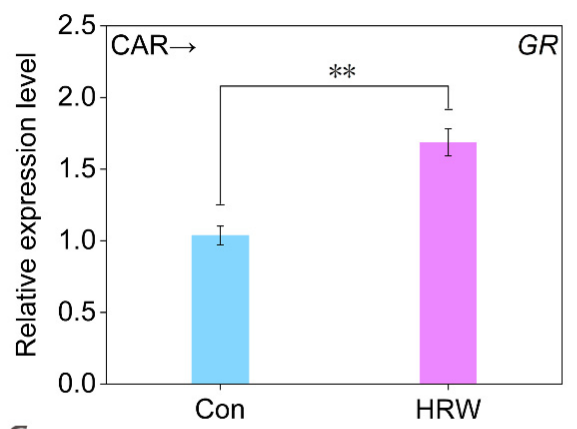

C

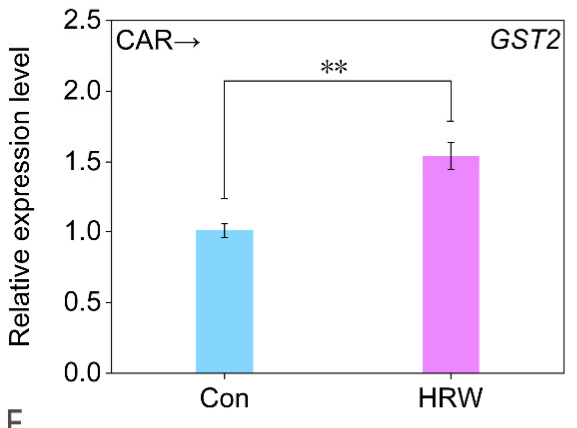

$\mathrm{E}$

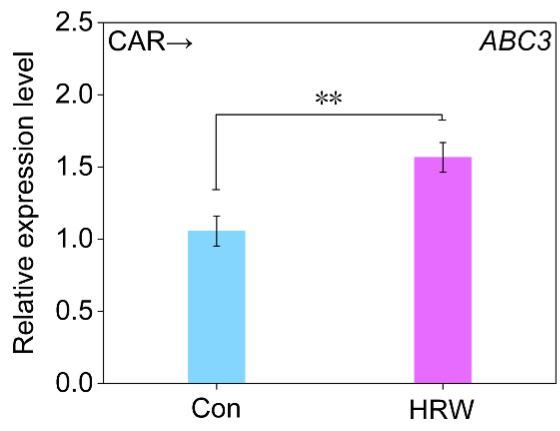

B

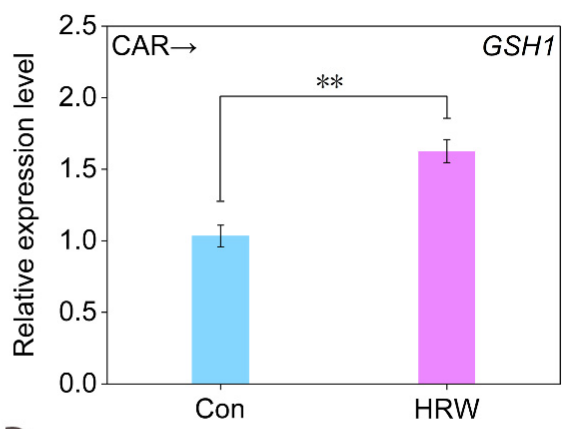

D

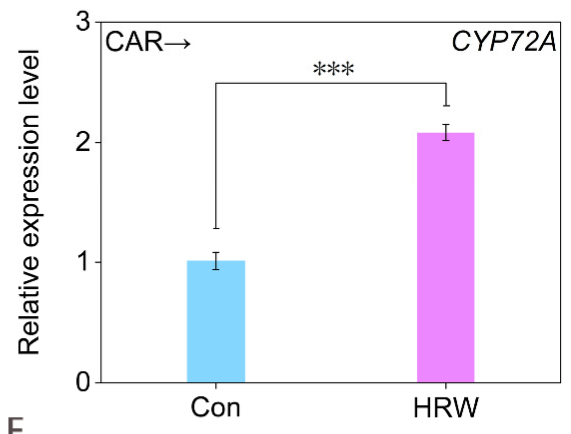

$\mathrm{F}$

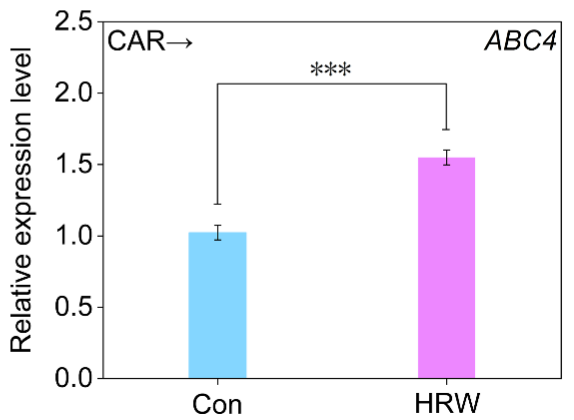

Figure 5. Changes in the transcription levels of GSH-dependent genes and detoxification genes. Tomato seedlings at the six-leaves stage were treated with $10.46 \mathrm{mM} \mathrm{CAR}$ for $24 \mathrm{~h}$, followed by treatment with $\mathrm{dH}_{2} \mathrm{O}$ (Con) or HRW. After $24 \mathrm{~h}$ of treatment, GR (A), GSH1 (B), GST2 (C), CYP72A (D), $A B C 3(\mathbf{E})$, and $A B C 4(\mathbf{F})$ transcript levels were analyzed by RT-qPCR. Error bars represent the standard deviation (SD; $\mathrm{n}=3$ ). ${ }^{* *}$ and ${ }^{* *}$ indicate significant difference results at $p<0.01$ or $p<0.001$ analyzed by independent-sample $t$-test.

Meanwhile, three detoxification genes, including $C Y P 72 A, A B C 3$, and $A B C 4$, were selected to evaluate their involvement of exogenous $\mathrm{H}_{2}$ control of CAR degradation. Among these, CYP72A encodes one of the members of cytochrome P450s, which are indispensable for hormone synthesis and detoxification in both animals and plants [43]. ATP-binding cassette $(\mathrm{ABC})$ transporters also participated in the detoxification of environmental pollutants [44,45]. Similarly, we further observed that in the presence of CAR, the expression of CYP72A (Figure 5D), $A B C 3$ (Figure 5E), and $A B C 4$ (Figure 5F) were significantly intensified by HRW, which were also correlated with the increased degradation of CAR (Figure 1A).

\subsection{CAR-Triggered Redox Imbalance Was Abolished by HRW}

For pesticide-induced phytotoxicity, ample evidence revealed that insecticides could influence redox balance, including resulting in reactive oxygen species (ROS) production and oxidative damage, in both animal and plant cells [46]. RT-qPCR results showed that CAT1 (encoding catalase), G-POD (encoding peroxidase), APX1 (encoding ascorbate peroxidase), $\mathrm{Cu} / \mathrm{Zn}$-SOD (encoding superoxide dismutase), MDHAR (encoding monodehy- 
droascorbate reductase), and DHAR (encoding dehydroascorbate reductase) genes (Zhou et al., 2017) were up-regulated after applying CAR (Figure S5). Furthermore, the combined treatment of CAR and HRW induced the transcription of the above-mentioned genes more strongly than CAR or HRW alone, indicating an additive effect of CAR and HRW on the induction.

Subsequent results showed that in the presence of either HRW or GSH, both $\mathrm{H}_{2} \mathrm{O}_{2}$ and $\mathrm{O}_{2}{ }^{-}$distribution (two important components of ROS; Figure S4B,C) and TBARS accumulation (an index related to oxidative damage; Figure S4D) were found to be abolished in CAR-treated tomato leaves, indicating the reconstructing redox homeostasis achieved by both HRW and GSH. These effects were sensitive to the removal of endogenous GSH by the addition of BSO, thus further emphasizing the participation of GSH. Similar tendencies were found in the changes of four antioxidant enzymes activities, including superoxide dismutase (SOD; Figure S4E), catalase (CAT; Figure S4F), ascorbate peroxidase (APX; Figure $\mathrm{S} 4 \mathrm{G}$ ), and guaiacol peroxidase (POD; Figure $\mathrm{S} 4 \mathrm{H})$.

\subsection{Genetic Evidence Revealed That Endogenous Molecular Hydrogen Can Positively Influence Carbendazim Degradation via GSH}

Exogenously applied molecular hydrogen may not faithfully mimic the function of endogenous $\mathrm{H}_{2}$ [22]. Thus, the genetic-based approach, using genetic materials with altered endogenous $\mathrm{H}_{2}$ levels, is likely to be more accurate for dissecting the nature function of molecular hydrogen, although its metabolism is still not fully elucidated in plants [11].

In the previous reports, the expression of hydrogenase 1 gene from Chlamydomonas reinhardtii (CrHYD1) in Arabidopsis represents an interesting method to assess the functions of endogenous production of $\mathrm{H}_{2}$ in plant cells, since molecular hydrogen derived from CrHYD1 expression could modify the stomatal closure [20] and improve salinity tolerance [19]. Here, compared to those in the wild-type (WT) with or without being transformed with the empty vector (EV), six CrHYD1 lines not only showed increased $\mathrm{H}_{2}$ production in the presence of CAR (Figure S6), but importantly, displayed the lower residues of CAR in leaves, especially CrHYD1-3, CrHYD1-5, and CrHYD1-6 (Figure 6A), and similar beneficial roles of endogenous $\mathrm{H}_{2}$ were discovered according to the changes in stomatal bioassays [20] and salinity phenotypic analysis [19]. Under the identical treatments, contrasting changes in endogenous GSH were also observed (Figure 6B), thus reflecting the possible negative correlation between CAR residues and GSH contents. This deduction was further supported by the ones exogenously applied with either GSH or BSO after the spraying with CAR in the above transgenic lines and wild-type plants. For example, after the addition of GSH, the decreased CAR residues and increased GSH contents observed in transgenic lines were differentially intensified. Contrasting results were found when BSO was applied, which could inhibit endogenous GSH biosynthesis. The above results clearly provided genetic evidence, showing that endogenous $\mathrm{H}_{2}$ is an endogenous regulator for CAR degradation in a GSH-dependent fashion.

In summary, our results clearly demonstrated that either exogenously applied or endogenously increased molecular hydrogen can decrease CAR residues in plant leaves. The present findings also indicated the possible role of GSH-dependent pathway in the detoxification of CAR, although a corresponding mechanism has not been fully elucidated.

Although several reports discovered that both brassinosteroids [40] and melatonin [26] could help plants degrade pesticides, the application with HRW without using the above conventional chemical additives might be more environmentally friendly for sustainable agriculture. More importantly, this study opened a new way for molecular hydrogen application to degrade the systemic fungicide CAR in a crop. 
A

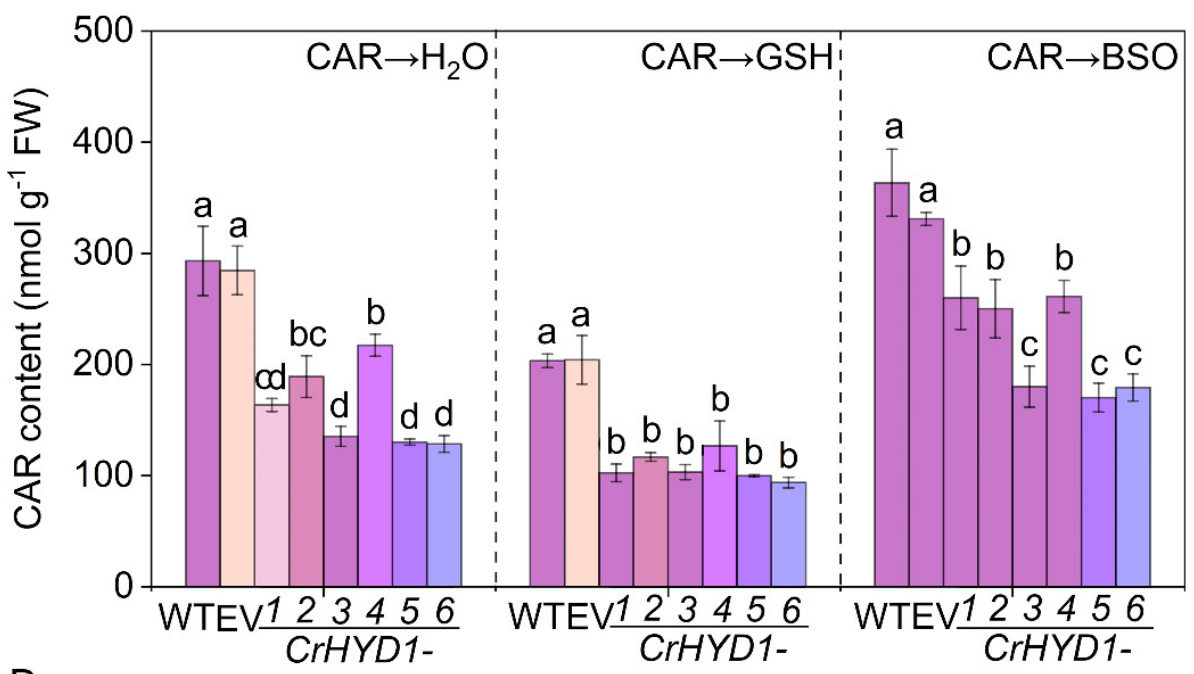

B

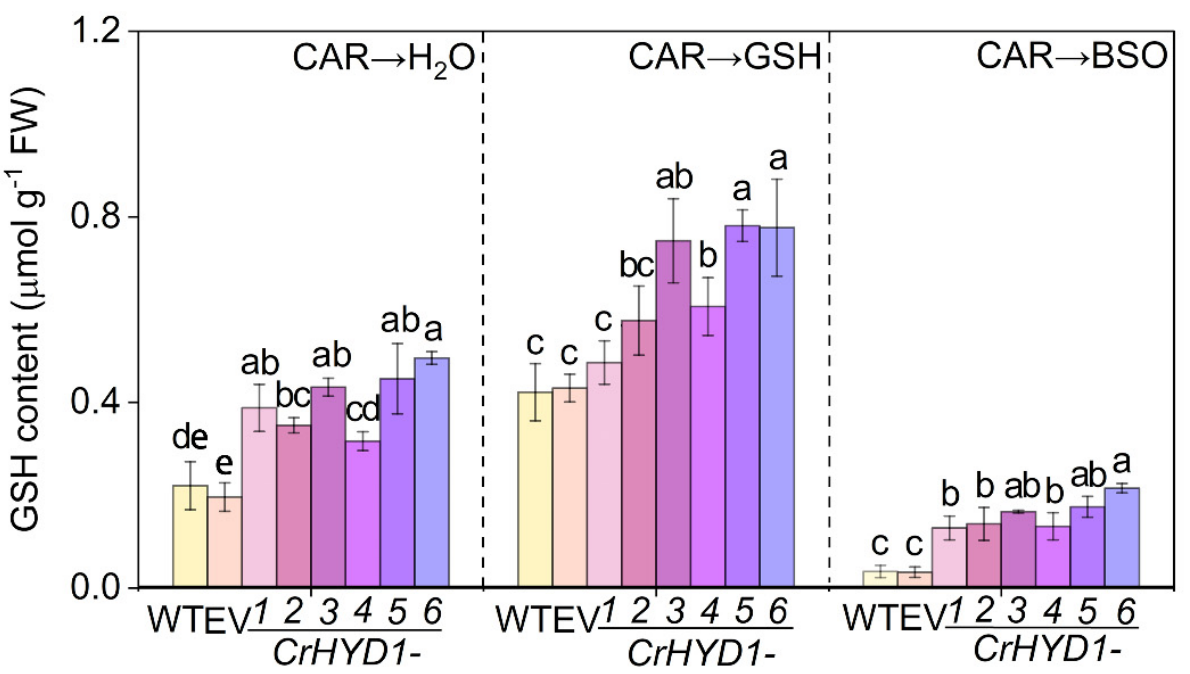

Figure 6. Genetic evidence showing the important role of endogenous molecular hydrogen in promoting the degradation of CAR via GSH synthesis. After Arabidopsis seedlings were sprayed with $10.46 \mathrm{mM} \mathrm{CAR}$ for $24 \mathrm{~h}$, seedlings were treated with $\mathrm{dH}_{2} \mathrm{O}$ (Con), GSH, or BSO for $24 \mathrm{~h}$. Afterwards, CAR residues (A) and GSH content $(\mathbf{B})$ were measured. The error bars represent the SDs $(\mathrm{n}=3 ; 20$ plants/treatment/repeat). Different letters indicate significantly different values $(p<0.05$ according to Tukey's multiple test).

\section{Materials and Methods}

\subsection{Chemicals}

DL-Buthionine-S (BSO; CAS 83730-53-4; purity $\geq 97 \%$ ) and reduced glutathione (GSH; CAS 27025-41-8; purity $\geq 98 \%$ ) were purchased from Sigma-Aldrich (St. Louis, MO, USA). Carbendazim (CAR; 50\% active ingredient) was obtained from Yingkouleike (Liaoning, China).

\subsection{Plant Material, Growth Conditions, and Treatments}

According to the previous methods [47], five-day-old tomato (Solanum lycopersicum L. $\mathrm{cv}$. baiguoqiangfeng) seedlings were transferred to a flowerpot containing a mixture of peat and vermiculite $(3: 1 ; v / v)$ and were cultivated in a growth chamber with a light intensity of $200 \mu \mathrm{mol} \mathrm{m}{ }^{-2} \mathrm{~s}^{-1}$ under a light cycle of $14 \mathrm{~h}$ of light and $10 \mathrm{~h}$ of dark at $24{ }^{\circ} \mathrm{C}$. Full-strength Hoagland's nutrient solution was replaced every two days until six true leaves were grown. 
The CrHYD1 transgenic strain expressed the hydrogenase1 gene from C. reinhardtii in Arabidopsis plants under the control of the cauliflower mosaic virus (CaMV) 35S promoter [20]. Seven-day-old Arabidopsis seedlings including wild-type, control plants transformed with the empty vector (EV), and six CrHYD1 transgenic lines (CrHYD1-1, CrHYD1-2, CrHYD1-3, CrHYD1-4, CrHYD1-5, and CrHYD1-6) were cultivated in a growth chamber with a light intensity of $150 \mu \mathrm{mol} \mathrm{m}{ }^{-2} \mathrm{~s}^{-1}$ under a light cycle of $16 \mathrm{~h}$ of light and $8 \mathrm{~h}$ of dark at $23^{\circ} \mathrm{C}$ for 6 weeks.

In order to elucidate the interaction between molecular hydrogen and CAR degradation (Figure 1) and whether GSH metabolism is stimulated by molecular hydrogen (Figure 4), CAR was dissolved in distilled water to prepare a solution of $10.46 \mathrm{mM}$ (the concentration used in practical applications) and further sprayed on tomato leaves [34], with $20 \mathrm{~mL}$ CAR used for each potted plant. After $24 \mathrm{~h}$ treatment, the above potted plants were divided into two groups and placed in two identical trays (20-40 pots for each). The two trays were filled with $500 \mathrm{~mL} \mathrm{dH}_{2} \mathrm{O}$ or $\mathrm{HRW}$, respectively.

In order to assess whether the CAR degradation achieved by molecular hydrogen was related to GSH metabolism (Figures 4 and 6), or altered the redox balance (Figure S4), $10.46 \mathrm{mM}$ CAR was used, with $20 \mathrm{~mL}$ CAR sprayed for each potted plant. After $24 \mathrm{~h}$ of treatment, the above potted plants were divided into six groups, and respectively placed in six identical trays (20-40 pots for each).

Four groups were respectively filled with $500 \mathrm{~mL}$ distilled water, and each potted plant was sprayed with $5 \mathrm{~mL}$ distilled water containing an equal ratio of organic solvent $\left(\mathrm{CAR} \rightarrow \mathrm{dH}_{2} \mathrm{O} / \mathrm{Con}\right)$, or sprayed with $5 \mathrm{~mL} 5 \mathrm{mM} \mathrm{GSH}(\mathrm{CAR} \rightarrow \mathrm{GSH})$, or sprayed with $5 \mathrm{~mL}$ $5 \mathrm{mM}$ GSH and $5 \mathrm{~mL} 1 \mathrm{mM}$ BSO $(\mathrm{CAR} \rightarrow \mathrm{GSH}+\mathrm{BSO})$, or sprayed with $5 \mathrm{~mL} 1 \mathrm{mM}$ BSO $(\mathrm{CAR} \rightarrow \mathrm{BSO})$.

Two other groups were respectively filled with $500 \mathrm{~mL} \mathrm{HRW}$, and each potted plant was sprayed with $5 \mathrm{~mL}$ distilled water containing an equal ratio of organic solvent $(\mathrm{CAR} \rightarrow \mathrm{HRW})$, or sprayed with $5 \mathrm{~mL} 1 \mathrm{mM}$ BSO $(\mathrm{CAR} \rightarrow \mathrm{HRW}+\mathrm{BSO})$.

\subsection{Preparation of Hydrogen-Rich Water}

According to the previous method [22], the saturated hydrogen-rich water (HRW) was prepared by using a SHC-300 $\mathrm{H}_{2}$ generator (Saikesaisi Hydrogen Energy Co., Ltd., Jinan, China). The $\mathrm{H}_{2}$ concentration in the above $\mathrm{HRW}$ was about $0.78 \mathrm{mM}$, and this saturated solution was applied subsequently.

\subsection{Determination of $\mathrm{H}_{2}$ Content}

Endogenous $\mathrm{H}_{2}$ content was measured with headspace gas chromatography (Tianmei GC7900 equipped with a thermal conductivity detector, Tianmei Scientific Instrument Co., Ltd., Shanghai, China) as described previously [48].

\subsection{Determination of GSH Content by UPLC Analysis}

According to previous methods [49], the GSH contents in leaves were determined with ultra-high performance liquid chromatography (UPLC; Agilent 1290, Agilent, Palo Alto, CA, USA). Total GSH and GSSG contents were determined by UPLC, and reduced GSH content was estimated from the difference between total GSH and GSSG.

\subsection{Determination of CAR Residues in Tomato Leaves}

CAR residues were determined by UPLC (Agilent 1290, Agilent, Palo Alto, CA, USA) [26]. The wavelength of detection was $280 \mathrm{~nm}$, and the injection volume was $2 \mu \mathrm{L}$.

\subsection{Indoor Toxicity Assessment and Experiment of Early Blight Resistance}

According to a previous method [50], indoor toxicity has been determined. Alternaria solani (Shanghai Bioresource Collection Center, SHBCC, Shanghai, China) was inoculated into the center of potato dextrose agar (PDA) mediums containing $0,2.62,5.23,10.46$, or $20.92 \mathrm{mM} \mathrm{CAR}$ at $28^{\circ} \mathrm{C}$. Organic membrane filters with the pore size of $0.22 \mu \mathrm{m}$ were used 
to filter HRW and distilled water, which were added to the culture medium. The colony diameter was determined after the incubation for 10 days.

After Alternaria solani was propagated on PDA mediums for 10 days, $2 \mathrm{~mL}$ of sterile water was added, and the spore was slowly scraped with a microscope slide. After inoculation, the spore concentration of the suspension was adjusted to $1 \times 10^{4}$ conidia $\mathrm{mL}^{-1}$, which was sprayed on tomato seedlings at the six-leaves stage [51]. The disease rate of leaves was calculated after $15 \mathrm{~d}$ of treatment [52].

\subsection{Analysis of the GSH Cycle}

According to the previous method [53], the activity of GR (glutathione reductase) was analyzed by detecting the rate of decrease in the absorbance of $340 \mathrm{~nm}$. GST (glutathione $S$-transferase) and $\gamma$-ECS ( $\gamma$-glutamylcysteine synthetase) activities were assayed with GST and $\gamma$-ECS activity kit (Nanjing JianCheng Bioengineering Institute, Nanjing, China). One unit (U) of $\gamma$-ECS activity was defined as the production of $1 \mu \mathrm{mol}$ inorganic phosphorus per milligram of tissue protein per hour.

\subsection{RT-qPCR Determination of Transcript Levels of Genes}

After the isolation of total RNA and cDNA synthesis, real-time quantitative PCR (RTqPCR) was performed [54], and the gene-specific primers were listed in Table S1. GADPH was used as an internal control gene. Three technical replicates of RT-qPCR were performed per gene-specific primers pair.

\subsection{Statistical Analysis}

Statistical analysis was performed using IBM SPSS Statistics 16.0 software. Statistical significance was analyzed by ANOVA analysis in combination with Tukey's multiple test $(p<0.05)$ or independent-sample $t$-test. ${ }^{* *}$ and ${ }^{* * *}$ indicate significant difference results at $p<0.01$ or $p<0.001$.

\section{Conclusions}

The above molecular and genetic evidence demonstrated that $\mathrm{H}_{2}$ could promote the CAR degradation in plants. GSH operates a downstream molecule functioning in the above process. In addition, molecular hydrogen could effectively enhance plant antioxidant capacity, thus reestablishing redox balance. Importantly, the results from this study will assist and promote further efforts to bring the findings of basic hydrogen biology research to hydrogen-based agriculture, thus meeting the dietary needs of 7.6 billion people in a healthy and sustainable manner.

Supplementary Materials: The following supporting information can be downloaded at: https: //www.mdpi.com/article/10.3390/plants11050621/s1, Table S1: The sequences primer sequences for qPCR; Figure S1: Time curve of CAR absorption in tomato leaves; Figure S2: Molecular hydrogendecreased CAR residues might be a universal event; Figure S3: GSH could alleviate the photoinhibition of CAR on tomato leaves; Figure S4: Changes in redox homeostasis; Figure S5: Comparison of expression of antioxidant genes; Figure S6: H2 production in WT, EV, and six CrHYD1 lines. Nonprotein thiol content was determined as previously described [55]. The photosynthetic parameters of tomato leaves were determined according to the method [21,56,57]. Antioxidant index of tomato leaves was determined according to the method [28,58-60].

Author Contributions: T.Z.: writing—original draft, methodology, formal analysis. Y.W.: methodology, formal analysis. Z.Z.: data curation. S.X.: methodology. W.S.: formal analysis, supervision, writing - review and editing. All authors have read and agreed to the published version of the manuscript.

Funding: This work was supported by the Funding from Center of Hydrogen Science, Shanghai Jiao Tong University, and Foshan Agriculture Science and Technology Project (Foshan City Budget No. 140, 2019.)

Institutional Review Board Statement: Not applicable. 
Informed Consent Statement: Not applicable.

Data Availability Statement: Data is contained within the article or supplementary material.

Conflicts of Interest: The authors declare that they have no known competing financial interest or personal relationships that could have appeared to influence the work reported in this paper.

\section{References}

1. Oerke, E.C. Crop losses to pests. J. Agric. Sci. 2006, 144, 31-43. [CrossRef]

2. Lee, S.J.; Mehler, L.; Beckman, J.; Diebolt-Brown, B.; Prado, J.; Lackovic, M.; Waltz, J.; Mulay, P.; Schwartz, A.; Mitchell, Y.; et al. Acute pesticide illnesses associated with off-target pesticide drift from agricultural applications: 11 states, 1998-2006. Environ. Health Perspect. 2011, 119, 1162-1169. [CrossRef]

3. European Food Safety Authority (EFSA). Conclusion on the peer review of the pesticide risk assessment of the active substance carbendazim. EFSA J. 2010, 8, 1598. [CrossRef]

4. Davidse, L.C. Benzimidazole fungicides: Mechanism of action and biological impact. Annu. Rev. Phytopathol. 1986, 24, 43-65. [CrossRef]

5. Zhang, X.; Huang, Y.; Harvey, P.R.; Li, H.; Ren, Y.; Li, J.; Wang, J.; Yang, H. Isolation and characterization of carbendazim-degrading Rhodococcus erythropolis djl-11. PLoS ONE 2013, 8, e74810. [CrossRef]

6. Singh, S.; Singh, N.; Kumar, V.; Datta, S.; Wani, A.B.; Singh, D.; Singh, K.; Singh, J. Toxicity, monitoring and biodegradation of the fungicide carbendazim. Environ. Chem. Lett. 2016, 14, 317-329. [CrossRef]

7. Besson-Barda, A.; Courtoisa, C.; Gauthiera, A.; Dahana, J.; Dobrowolskab, G.; Jeandrozc, S.; Pugin, A.; Wendehenne, D. Nitric oxide in plants: Production and cross-talk with $\mathrm{Ca}^{2+}$ signaling. Mol. Plant 2008, 1, 218-228. [CrossRef]

8. Yin, Y.; Zhou, Y.; Zhou, Y.; Shi, K.; Zhou, J.; Yu, Y.; Yu, J.; Xia, X. Interplay between mitogen-activated protein kinase and nitric oxide in brassinosteroid-induced pesticide metabolism in Solanum lycopersicum. J. Hazard. Mater. 2016, 316, 221-231. [CrossRef]

9. Ohsawa, I.; Ishikawa, M.; Takahashi, K.; Watanabe, M.; Nishimaki, K.; Yamagata, K.; Katsura, K.; Katayama, Y.; Asoh, S.; Ohta, S. Hydrogen acts as a therapeutic antioxidant by selectively reducing cytotoxic oxygen radicals. Nat. Med. 2007, 13, 688-694. [CrossRef]

10. Ohta, S. Molecular hydrogen as a preventive and therapeutic medical gas: Initiation, development and potential of hydrogen medicine. Pharmacol. Ther. 2014, 144, 1-11. [CrossRef]

11. Shen, W.; Sun, X.J. Hydrogen biology: It is just beginning. Chin. J. Biochem. Mol. Biol. 2019, 35, 1037-1050. [CrossRef]

12. Gaffron, H. Reduction of carbon dioxide with molecular hydrogen in green algae. Nature 1939, 143, 204-205. [CrossRef]

13. Renwick, G.M.; Giumarro, C.; Siegel, S.M. Hydrogen metabolism in higher plants. Plant Physiol. 1964, 39, 303-306. [CrossRef] [PubMed]

14. Hunt, S.; Layzell, D.B. Gas-exchange of legume nodules and the regulation of nitrogenase activity. Annu. Rev. Plant Physiol. Plant Mol. Biol. 1993, 44, 483-511. [CrossRef]

15. Wang, Y.Q.; Liu, Y.H.; Wang, S.; Du, H.M.; Shen, W. Hydrogen agronomy: Research progress and prospects. J. Zhejiang Univ. Sci. B 2020, 21, 841-855. [CrossRef]

16. Li, L.; Lou, W.; Kong, L.; Shen, W. Hydrogen commonly applicable from medicine to agriculture: From molecular mechanisms to the field. Curr. Pharm. Des. 2021, 27, 747-759. [CrossRef]

17. Wang, Y.; Zhang, T.; Wang, J.; Xu, S.; Shen, W. Regulation of chlorothalonil degradation by molecular hydrogen. J. Hazard. Mater. 2022, 424, 127291. [CrossRef]

18. Wang, Z.W.; Huang, J.; Chen, J.Y.; Li, F.L. Time-dependent movement and distribution of chlorothalonil and chlorpyrifos in tomatoes. Ecotoxicol. Environ. Saf. 2013, 93, 107-111. [CrossRef]

19. Su, J.; Yang, X.; Shao, Y.; Chen, Z.; Shen, W. Molecular hydrogen-induced salinity tolerance requires melatonin signaling in Arabidopsis thaliana. Plant Cell Environ. 2021, 44, 476-490. [CrossRef]

20. Zhang, Y.; Cheng, P.; Wang, Y.; Li, Y.; Su, J.; Chen, Z.; Yu, X.; Shen, W. Genetic elucidation of hydrogen signaling in plant osmotic tolerance and stomatal closure via hydrogen sulfide. Free Radic. Biol. Med. 2020, 161, 1-14. [CrossRef]

21. Su, J.; Zhang, Y.; Nie, Y.; Cheng, D.; Wang, R.; Hu, H.; Chen, J.; Zhang, J.; Du, Y.; Shen, W. Hydrogen-induced osmotic tolerance isassociated with nitric oxide-mediated proline accumulation and reestablishment of redox balance in alfalfa seedlings. Environ. Exp. Bot. 2018, 147, 249-260. [CrossRef]

22. Xie, Y.; Mao, Y.; Zhang, W.; Lai, D.; Wang, Q.; Shen, W. Reactive oxygen species-dependent nitric oxide production contributes to hydrogen-promoted stomatal closure in Arabidopsis. Plant Physiol. 2014, 165, 759-773. [CrossRef]

23. Cao, Z.; Duan, X.; Yao, P.; Cui, W.; Cheng, D.; Zhang, J.; Jin, Q.; Chen, J.; Dai, T.; Shen, W. Hydrogen gas is involved in auxin-induced lateral root formation by modulating nitric oxide synthesis. Int. J. Mol. Sci. 2017, 18, 2084. [CrossRef] [PubMed]

24. Liu, F.; Lou, W.; Wang, J.; Li, Q.; Shen, W. Glutathione produced by $\gamma$-glutamyl cysteine synthetase acts downstream of hydrogen to positively influence lateral root branching. Plant Physiol. Biochem. 2021, 167, 68-76. [CrossRef] [PubMed]

25. De Wilde, T.; Spanoghe, P.; Ryckeboer, J.; Jaeken, P.; Springael, D. Sorption characteristics of pesticides on matrix substrates used in biopurification systems. Chemosphere 2009, 75, 100-108. [CrossRef] 
26. Yan, Y.; Sun, S.; Zhao, N.; Yang, W.; Shi, Q.; Gong, B. COMT1 overexpression resulting in increased melatonin biosynthesis contributes to the alleviation of carbendazim phytotoxicity and residues in tomato plants. Environ. Pollut. 2019, $252,51-61$. [CrossRef]

27. Xu, S.; Jiang, Y.; Cui, W.; Jin, Q.; Zhang, Y.; Bu, D.; Fu, J.; Wang, R.; Zhou, F.; Shen, W. Hydrogen enhances adaptation of rice seedlings to cold stress via the reestablishment of redox homeostasis mediated by miRNA expression. Plant Soil 2017, 414, 53-67. [CrossRef]

28. Jin, Q.; Zhu, K.; Cui, W.; Xie, Y.; Han, B.; Shen, W. Hydrogen gas acts as a novel bioactive molecule in enhancing plant tolerance to paraquat-induced oxidative stress via the modulation of heme oxygenase-1 signalling system. Plant Cell Environ. 2013, 36, 956-969. [CrossRef]

29. Zulfqar, F.; Russell, G.; Hancock, J.T. Molecular hydrogen in agriculture. Planta 2021, 254, 56. [CrossRef]

30. Xu, X.; Chen, J.; Li, B.; Tang, L. Carbendazim residues in vegetables in China between 2014 and 2016 and a chronic carbendazim exposure risk assessment. Food Control 2018, 91, 20-25. [CrossRef]

31. Chaerani, R.; Voorrips, R.E. Tomato early blight (Alternaria solani): The pathogen, genetics, and breeding for resistance. J. Gen. Plant Pathol. 2006, 72, 335-347. [CrossRef]

32. Coleman, J.O.D.; Randall, R.; Blake-Kalff, M.M.A. Detoxification of xenobiotics in plant cells by glutathione conjugation and vacuolar compartmenttaiization: A fluorescent assay using monochiorobimane. Plant Cell Environ. 1997, 20, 449-460. [CrossRef]

33. Yu, G.B.; Zhang, Y.; Ahammeda, G.J.; Xia, X.J.; Mao, W.H.; Shi, K.; Zhou, Y.H.; Yu, J.Q. Glutathione biosynthesis and regeneration play an important role in the metabolism of chlorothalonil in tomato. Chemosphere 2013, 90, 2563-2570. [CrossRef] [PubMed]

34. Wang, J.; Jiang, Y.; Chen, S.; Xia, X.; Shi, K.; Zhou, Y.; Yu, Y.; Yu, J. The different responses of glutathione-dependent detoxification pathway to fungicide chlorothalonil and carbendazim in tomato leaves. Chemosphere 2010, 79, 958-965. [CrossRef] [PubMed]

35. Seyfried, J.; Soldner, F.; Schulz, J.B.; Klockgether, T.; Kovar, K.A.; Wüllner, U. Differential effects of ${ }_{\mathrm{L}}$-buthionine sulfoximine and ethacrynic acid on glutathione levels and mitochondrial function in PC12 cells. Neurosci. Lett. 1999, 264, 1-4. [CrossRef]

36. Vernoux, T.; Wilson, R.C.; Seeley, K.A.; Reichheld, J.P.; Muroy, S.; Brown, S.; Maughan, S.C.; Cobbett, C.S.; Montagu, M.V.; Inzé, D.; et al. The ROOT MERISTEMLESS1/CADMIUM SENSITIVE2 Gene defines a glutathione-dependent pathway involved in initiation and maintenance of cell division during postembryonic root development. Plant Cell 2000, 12, 97-109. [CrossRef]

37. Cui, W.; Gao, C.; Fang, P.; Lin, G.; Shen, W. Alleviation of cadmium toxicity in Medicago sativa by hydrogen-rich water. J. Hazard. Mater. 2013, 260, 715-724. [CrossRef]

38. Noctor, G.; Mhamdi, A.; Chaouch, S.; Han, Y.; Neukermans, J.; Marquez-Garcia, B.; Queval, G.; Foyer, C.H. Glutathione in plants: An integrated overview. Plant Cell Environ. 2012, 35, 454-484. [CrossRef]

39. Marrs, K.A. The functions and regulation of glutathione S-transferases in plants. Annu. Rev. Plant Physiol. Plant Mol. Biol. 1996, 47, 127-158. [CrossRef]

40. Xia, X.; Zhang, Y.; Wu, J.; Wang, J.; Zhou, Y.; Shi, K.; Yu, Y.; Yu, J. Brassinosteroids promote metabolism of pesticides in cucumber. J. Agric. Food Chem. 2009, 57, 8406-8413. [CrossRef]

41. Yu, G.; Wei, J.; Chen, X.; Li, X.; Liu, X.; Ye, X.; Zhang, N.; Sun, W. The effect of glutathione in the regulation of the degradation of residual fungicide in tomato. Int. J. Agric. Biol. 2018, 20, 1873-1879. [CrossRef]

42. Cobbett, C.S.; May, M.J.; Howden, R.; Rolls, B. The glutathione-deficient, cadmium-sensitive mutant, cad2-1, of Arabidopsis thaliana is deficient in $\gamma$-glutamylcysteine synthetase. Plant J. 1998, 16, 73-78. [CrossRef] [PubMed]

43. Religia, P.; Nguyen, N.D.; Nong, Q.D.; Matsuura, T.; Kato, Y.; Watanabe, H. Mutation of the cytochrome P450 CYP360A8 gene increases sensitivity to paraquat in Daphnia magn. Environ. Toxicol. Chem. 2021, 40, 1279-1288. [CrossRef]

44. Deen, M.; Vries, E.G.; Timens, W.; Scheper, R.J.; Timmer-Bosscha, H.; Postma, D.S. ATP-binding cassette (ABC) transporters in normal and pathological lung. Resp. Res. 2005, 6, 59. [CrossRef] [PubMed]

45. Rea, R.A. Plant ATP-binding cassette transporters. Annu. Rev. Plant Biol. 2007, 58, 347-375. [CrossRef] [PubMed]

46. Ahammed, G.J.; Ruan, Y.P.; Zhou, J.; Xia, X.J.; Shi, K.; Zhou, Y.H.; Yu, J.Q. Brassinosteroid alleviates polychlorinated biphenylsinduced oxidative stress by enhancing antioxidant enzymes activity in tomato. Chemosphere 2013, 90, 2645-2653. [CrossRef]

47. Mei, Y.; Chen, H.; Shen, W.; Huang, L. Hydrogen peroxide is involved in hydrogen sulfide-induced lateral root formation in tomato seedlings. BMC Plant Biol. 2017, 17, 162. [CrossRef]

48. Wang, Y.; Lv, P.; Kong, L.; Shen, W.; He, Q. Nanomaterial-mediated sustainable hydrogen supply induces lateral root formation via nitrate reductase-dependent nitric oxide. Chem. Eng. J. 2021, 405, 126905. [CrossRef]

49. Herschbach, C.; Pilch, B.; Tausz, M.; Rennenberg, H.; Grill, D. Metabolism of reduced and inorganic sulphur in pea cotyledons and distribution into developing seedlings. New Phytol. 2002, 153, 73-80. [CrossRef]

50. Chen, Y.; Lu, M.; Guo, D.; Zhai, Y.; Miao, D.; Yue, J.; Yuan, C.; Zhao, M.; An, D. Antifungal effect of magnolol and honokiol from Magnolia officinalis on Alternaria alternata causing tobacco brown spot. Molecules 2019, 24, 2140. [CrossRef]

51. Chaerani, R.; Groenwold, R.; Stam, P.; Voorrips, R.E. Assessment of early blight (Alternaria solani) resistance in tomato using a droplet inoculation method. J. Gen. Plant Pathol. 2007, 73, 96-103. [CrossRef]

52. Xue, Q.; Chen, Y.; Li, S.; Chen, L.; Ding, G.; Guo, D.; Guo, J. Evaluation of the strains of Acinetobacter and Enterobacter as potential biocontrol agents against Ralstonia wilt of tomato. Biol. Control 2009, 48, 252-258. [CrossRef]

53. Cakmak, I.; Marschner, H. Magnesium deficiency and high light intensity enhance activities of superoxide dismutase, ascorbate peroxidase, and glutathione reductase in bean leaves. Plant Physiol. 1992, 98, 1222-1227. [CrossRef] [PubMed] 
54. Livak, K.J.; Schmittgen, T.D. Analysis of relative gene expression data using real-time quantitative PCR and the $2^{-\Delta \Delta C}$ Tethod. Methods 2001, 25, 402-408. [CrossRef] [PubMed]

55. Qian, M.; Li, X.; Shen, Z. Adaptive copper tolerance in Elsholtzia haichowensis involves production of Cu-induced thiol peptides. Plant Growth Regul. 2005, 47, 65-73. [CrossRef]

56. Gong, B.; Li, X.; Bloszies, S.; Wen, D.; Sun, S.; Wei, M.; Li, Y.; Yang, F.; Shi, Q.; Wang, X. Sodic alkaline stress mitigation by interaction of nitric oxide and polyamines involves antioxidants and physiological strategies in Solanum lycopersicum. Free Radic. Biol. Med. 2014, 71, 36-48. [CrossRef]

57. Schreiber, U.; Schliwa, U.; Bilger, W. Continuous recording of photochemical and non-photochemical chlorophyll fluorescence quenching with a new type of modulation fluorometer. Photosynth. Res. 1986, 10, 51-62. [CrossRef]

58. Su, J.; Nie, Y.; Zhao, G.; Cheng, D.; Wang, R.; Chen, J.; Zhang, S.; Shen, W. Endogenous hydrogen gas delays petal senescence and extends the vase life of lisianthus cut flowers. Postharvest Biol. Technol. 2019, 147, 148-155. [CrossRef]

59. Gong, B.; Wen, D.; VandenLangenberg, K.; Wei, M.; Yang, F.; Shi, Q.; Wang, X. Comparative effects of $\mathrm{NaCl}$ and NaHCO3 stress on photosynthetic parameters, nutrient metabolism, and the antioxidant system in tomato leaves. Sci. Hortic. 2013, 157, 1-12. [CrossRef]

60. Bradford, M.M. A rapid and sensitive method for the quantitation of microgram quantities of protein utilizing the principle of protein-dye binding. Anal. Biochem. 1976, 72, 248-254. [CrossRef] 